\title{
Knowledge management and social media: A scientometrics survey
}

\author{
Ebrahim Zarei ${ }^{\mathrm{a}}$ and Armin Jabbarzadeh ${ }^{\mathrm{a}^{*}}$
}

${ }^{a}$ Business School, McMaster University, Ontario, Canada

\begin{tabular}{l}
${ }^{a}$ Business School, McMaster Universi \\
\hline C H R O N I C L E \\
\hline Article history: \\
Received: January 2, 2019 \\
Received in revised format: Janu- \\
ary 26, 2019 \\
Accepted: February 16, 2019 \\
Available online: \\
February 16, 2019 \\
\hline Keywords: \\
Social media \\
Knowledge sharing \\
Knowledge management \\
Scientometrics \\
Bibliometric \\
Bibliometrix R-package \\
\hline
\end{tabular}

\section{A B S T R A C T}

\begin{abstract}
The purpose of this research is to study the role of the social media for knowledge sharing. The study presents a comprehensive review of the researches associated with the effect of knowledge management in social media. The study uses Scopus database as a primary search engine and covers 1858 of highly cited articles over the period 1994-2019. The records are statistically analyzed and categorized in terms of various criteria using an open source software package named $R$. The findings show that researches have grown exponentially during the recent years and the trend has continued at relatively stable rates. Based on the survey, knowledge management is the keyword which has carried the highest citations followed by social media and social networking. Among the most cited articles, papers published by researchers in United States have received the highest citations, followed by United Kingdom and China.
\end{abstract}

(C) 2019 by the authors; licensee Growing Science, Canada.

\section{Introduction}

In the competitive world of today, knowledge has become a strategic source for many organizations. Davenport and Prusak (1998) believe that organizations must distinguish themselves from others based on what they know. Knowledge management (KM) has become a kind of fashion and management style since the 1990s and it is associated with the systematic and consistent process of coordinating the wideranging activities of the organization, including the acquisition, creation, storage, sharing and application of knowledge by individuals and groups to reach organizational objectives (Rastogi, 2000). The effect of KM projects on the overall success of the organization has been widely acknowledged. However, what factors and how they can succeed are questions which needs extensive investigation. Thus, in various researches conducted in this field, the effects of different factors on the success of management projects have been studied.

* Corresponding author

E-mail address: Jabbarza@mcmaster.ca (A. Jabbarzadeh) 
Among the various business policies, there are different issues which are effective in building an appropriate infrastructure and context to support the KM process. Human resource management policies concentrating on attracting and retaining talent are considered as a kind of organizational culture which embraces new ideas and learning.

KM achieves the objectives of the firm by optimally utilizing the knowledge or the capabilities of a firm to implement intellectual capital and collective knowledge to reach its objectives through a process including knowledge generation, knowledge sharing and use it with the help of technology. Moreover, Social media is one of the most essential issues associated with KM. Studies have shown that different countries have used social media in knowledge management Yates and Paquette (2010), explained how social media technology was used and how this tool was implemented to share information in an earthquake in different countries.

There is usually a difference in the use of social media in large organizations and small and medium enterprisess (SMEs). According to McAdam and Reid (2001), large organizations apply knowledge management based on social media than small firms do. In their study, large organizations were organized by more than 250 people and SMEs were managed by fewer than 250 people. Of course, SMEs have unique characteristics that affect these activities that lead to organizational effectiveness. The most important of these activities are associated with how they manage knowledge. The impact and usage of social media in SMEs have become important in recent years and social media has played an important role for the success of the firms. Therefore, SMEs can also use the social media to share information and exchange ideas. The results show that given the importance of SMEs in the economy, in Germany, for example, SMEs have gone to social media such as blogging, wikis, but there are still many problems with them to accept social media. Another issue is the impact of the cost-effective social media exchange on information sharing (Meske \& Stieglitz, 2013).

Another issue is that in general, social media makes information more accessible. In fact, the information sharing is initially considered as an alternative, and then continuously emerges into businerss structure through sharing information between less-known individuals (Majchrzak et al., 2013). Majchrzak et al. (2013) studied the effect os of using social media in knowledge management processes in metal industry. Social media tools such as Facebook reviews, wikis, and blogs, and knowledge management processes are the process of creating, disseminating, and using useful information. Also, the reasons for not using social media in the process of knowledge management and the benefits of using it, from the users' perspective working in these organizations was examined by Majchrzak et al. (2013). The research findings indicated that about half of the surveyed people implemented social media in their knowledge management each day. The use of the media became popular in terms of the number of times in both the metal industries and research institutes, respectively, and $70 \%$ and $47.1 \%$ of the people each year used these media in their knowledge management activities in the organization, respectively.

Location, motivation and social capital through the social networking business can reduce information sharing problems. These challenges include the place of business, the motivation to share information and social capital (Fulk \& Yuan, 2013). Social media has had a great impact on sport, which is reviewed by studying 70 articles on how information is shared and knowledge management is used in sport through social media. Three categories of social media in this case include behavioral, strategic, and focused on consumption. Social media in the field of sports management refers to the collection of communications between individuals and brands. Interest is very important in this regard and the present age has been called the "age of communication". In this era, mass communication has been transformed into a new form and has affected the developments of the human society, due to the application of communicative means, whose extent and influence is enormous. As part of the modern society structure and one of the most comprehensive and widely available media systems, the media plays an important role in all countries in various political, cultural, social, economic and other fields. 
From the point of view of knowledge management, learning from e-learning to social learning is essential for knowledge management. An important issue is the role of social capital in the media. The relationship between the use of social media and employees' creativity with the knowledge management approach is another issue and aims at examining the role of social media and the creativity of individuals.

\section{The propsoed study}

In this paper, we present a comprehensive bibliometrix study to learn more about different studies associated with the relationship between knowledge management and knowledge sharing. The study uses a bibliometrix software package embeded in $\mathrm{R}$ as a datamining package. Bibliometrix $\mathrm{R}$ package is a tool for quantitative research in scientometrics and bibliometrics. Bibliometrix package provides various routines for importing bibliographic data from Scopus, Clarivate Analytics' Web of Science, PubMed and Cochrane databases, performing bibliometric analysis and building data matrices for co-citation, coupling and scientific collaboration analysis (Aria \& Cuccurullo, 2017). The proposed study of this paper performs a survey on Scopus database using two keywords of "knowledge management" and "social media". We have collected the first 1858 records with the highest citations, imported into R-software package and analyzed the results.

\subsection{Annual Scientific Production}

With the objective of ascertaining the international evolution of the subject, a broad range of study was carried out. A total of 1858 original articles and reviews were published on this subject.

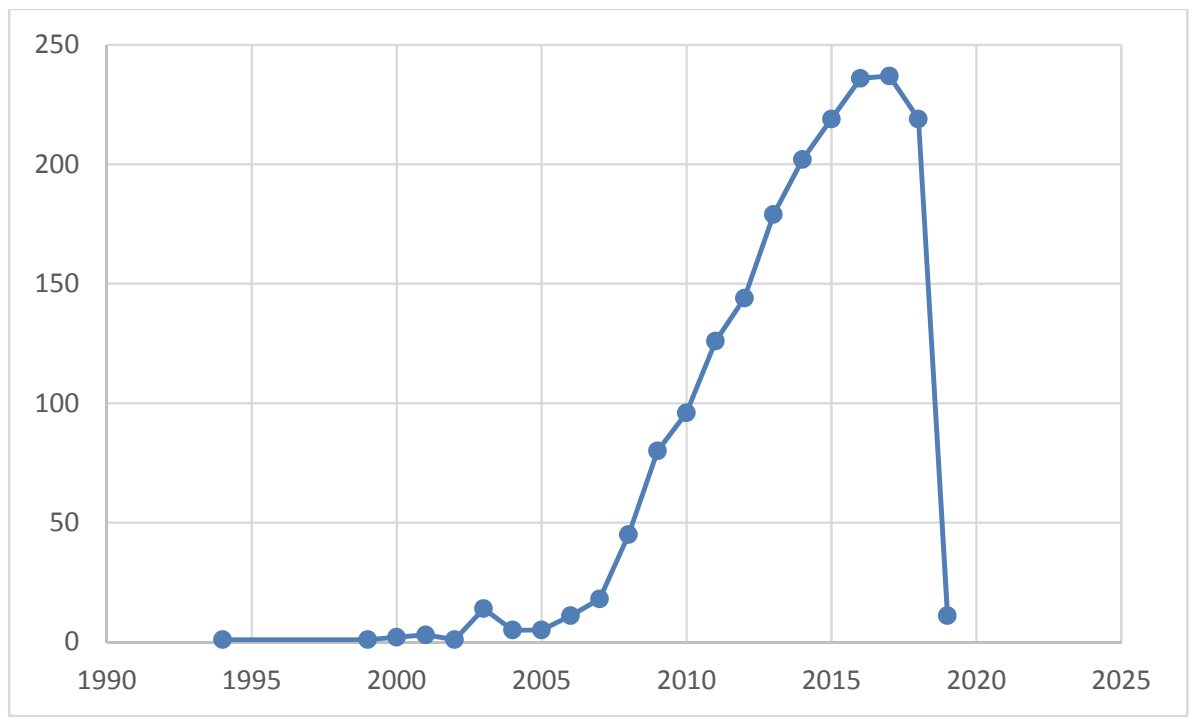

Fig. 1.The Scopus publications on the analysis of social media and knowledge management from 1994 to 2019

Fig. 1 shows the annual number of articles published in both the social media and knowledge management issues in the Scopus database for a period of 25 years, from 1994 to 2019. As can be seen, the production of content has been increasing in recent years.

\subsection{The themes in reviewed articles}

The search of articles on the Scopus site was accomplished with two keywords "Social Media" and "Promotion". In Scopus, there were 1856 articles related to these keywords. Then the articles were arranged according to the highest citation, and among them, we reviewed 130 articles which received the highest citations. In Table 1, we have presented the areas covered by all 130 articles. Fig. 2 shows the structure of the most popular words used in the literature. 
Table 1

Articles themes

\begin{tabular}{|c|c|c|c|c|c|c|c|c|c|c|c|c|c|c|c|c|c|c|}
\hline No. & Articles & $\begin{array}{l}\overrightarrow{0} \\
\stackrel{0}{0} \\
\Omega \\
\stackrel{0}{0} \\
\stackrel{0}{0} \\
\stackrel{0}{0}\end{array}$ & 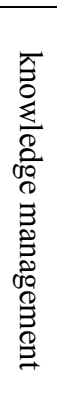 & 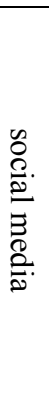 & 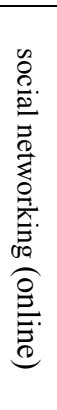 & 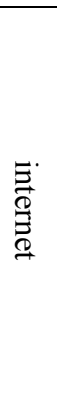 & 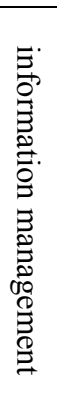 & 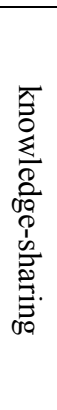 & $\begin{array}{l}\stackrel{2}{0} \\
\stackrel{0}{0} \\
\stackrel{0}{0} . \\
\stackrel{0}{g}\end{array}$ & 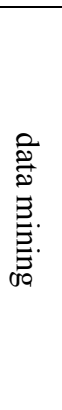 & 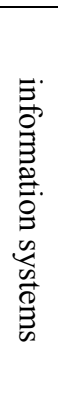 & 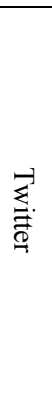 & 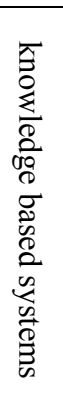 & 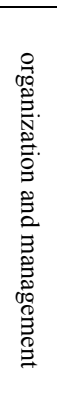 & 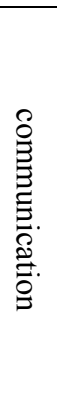 & 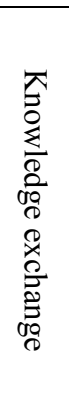 & 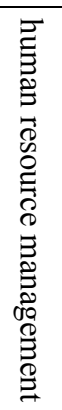 & 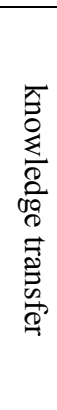 \\
\hline 1 & Straub, 1994 & 436 & $\sqrt{ }$ & $\sqrt{ }$ & & & & & & & & & & & & & & \\
\hline 2 & Yates \& Paquette, 2010 & 416 & $\sqrt{ }$ & $\sqrt{ }$ & & & & $\sqrt{ }$ & & & & & & & & & & \\
\hline 3 & Kane et al., 2010, 2012 & 283 & $\sqrt{ }$ & $\sqrt{ }$ & $\sqrt{ }$ & & & & & & & & & & & & & \\
\hline 4 & Rao, 2010 & 267 & $\sqrt{ }$ & $\sqrt{ }$ & $\sqrt{ }$ & & & & & $\sqrt{ }$ & & $\sqrt{ }$ & & & & & & \\
\hline 5 & Olsen, 2007 & 243 & $\sqrt{ }$ & & & & & & & & & & & & & & & \\
\hline 6 & Kamel Boulos, 2011 & 214 & & $\sqrt{ }$ & & $\sqrt{ }$ & & & & & & $\sqrt{ }$ & & $\sqrt{ }$ & & & & \\
\hline 7 & Mcadam, 2001 & 203 & $\sqrt{ }$ & & & & & & & & & & & & & & & \\
\hline 8 & Majchrzak et al., 2001 & 191 & & $\sqrt{ }$ & $\sqrt{ }$ & & & $\sqrt{ }$ & & & & & & & & & & \\
\hline 9 & Wei, 2012 & 174 & $\sqrt{ }$ & & & & & & & $\sqrt{ }$ & & & & & & & & \\
\hline 10 & Treude, 2011 & 173 & $\sqrt{ }$ & $\sqrt{ }$ & & $\sqrt{ }$ & & & $\sqrt{ }$ & & & & & & & $\sqrt{ }$ & & \\
\hline 11 & Bozeman, 2013 & 142 & $\sqrt{ }$ & $\sqrt{ }$ & $\sqrt{ }$ & $\sqrt{ }$ & $\sqrt{ }$ & & & & & & $\sqrt{ }$ & & & & & \\
\hline 12 & Leonardi, 2014 & 141 & $\sqrt{ }$ & & $\sqrt{ }$ & & & $\sqrt{ }$ & & & & & & & & & & \\
\hline 13 & Price et al., 2014 & 133 & 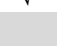 & $\sqrt{ }$ & & $\sqrt{ }$ & & & & & & & & & & & & \\
\hline 14 & Sartorius et al., 2010 & 133 & $\sqrt{ }$ & & & & & & & & & & & & & & & \\
\hline 15 & Tredinnick, 2006 & 133 & $\sqrt{ }$ & $\sqrt{ }$ & & $\sqrt{ }$ & $\sqrt{ }$ & & & & & & & & & & & \\
\hline 16 & Martín-de-Castro et al., 2011 & 130 & $\sqrt{ }$ & & & & & & & & & & & & & & & \\
\hline 17 & Saerbeck et al., 2010 & 130 & $\sqrt{ }$ & & & & & & $\sqrt{ }$ & & $\sqrt{ }$ & & & & & & & $\sqrt{ }$ \\
\hline 18 & Khoury \& Ioannidis, 2014 & 125 & $\sqrt{ }$ & $\sqrt{ }$ & & $\sqrt{ }$ & & & & & & & & & & & & \\
\hline 19 & Egbu et al., 2005 & 121 & $\sqrt{ }$ & & & & $\sqrt{ }$ & & & & & & $\sqrt{ }$ & & & & & \\
\hline 20 & Martinelli et al., 2008 & 119 & $\sqrt{ }$ & & & & & & & & & & & & & & & \\
\hline 21 & Barua et al., 2014 & 117 & $\sqrt{ }$ & & & & & & & & & & & & & & & \\
\hline 22 & Kinsella et al., 2011 & 117 & $\sqrt{ }$ & $\sqrt{ }$ & $\sqrt{ }$ & & & & & & & $\sqrt{ }$ & & & & & & \\
\hline 23 & Stellefson 2013 & 112 & & $\sqrt{ }$ & & $\sqrt{ }$ & & & & & & & & & & & & \\
\hline 24 & Popescu, 2010 & 111 & $\sqrt{ }$ & $\sqrt{ }$ & $\sqrt{ }$ & & & & & & & & & & & & & \\
\hline 25 & Peersman, 2011 & 106 & & $\sqrt{ }$ & $\sqrt{ }$ & & & & & & & & & & & & & \\
\hline 26 & Tang \& Liu, 2009 & 101 & $\sqrt{ }$ & $\sqrt{ }$ & & & & & & & & & & & & & & \\
\hline 27 & Mohammadi et al., 2014 & 100 & $\sqrt{ }$ & & & & & & & & & & & & & & & $\sqrt{ }$ \\
\hline 28 & Wu, 2013 & 100 & $\sqrt{ }$ & $\sqrt{ }$ & & & & & & & & & & & & & & \\
\hline 29 & Castrén, 2015 & 98 & & $\sqrt{ }$ & & & & & $\sqrt{ }$ & & & & & & & & & \\
\hline 30 & Goodchild et al., 2010 & 97 & $\sqrt{ }$ & & & & & & & & $\sqrt{ }$ & & & & & & & $\sqrt{ }$ \\
\hline 31 & Sizov, 2010 & 96 & & $\sqrt{ }$ & $\sqrt{ }$ & & & & & & & & & & & & & \\
\hline 32 & Wang et al., 2013 & 92 & $\sqrt{ }$ & & $\sqrt{ }$ & & & & & & & & $\sqrt{ }$ & & & & & \\
\hline 33 & Chua \& Banerjee, 2013 & 90 & $\sqrt{ }$ & $\sqrt{ }$ & & & & & & & & & & & & & & \\
\hline 34 & Bjerregaard, 2010 & 89 & $\sqrt{ }$ & & & & & & & & & & & & & $\sqrt{ }$ & & \\
\hline 35 & de Albuquerque et al., 2013 & 88 & & $\sqrt{ }$ & & & & & & & & $\sqrt{ }$ & & & & & & \\
\hline 36 & Gibbs et al., 2013 & 87 & $\sqrt{ }$ & $\sqrt{ }$ & & & & $\sqrt{ }$ & & & & & & & & & & \\
\hline 37 & Wang, 2011 & 84 & $\sqrt{ }$ & & & & & $\sqrt{ }$ & & & & & & & & & & \\
\hline 38 & Aboujaoude et al., 2015 & 79 & $\sqrt{ }$ & $\sqrt{ }$ & & $\sqrt{ }$ & & & & & & & & & & & & \\
\hline 39 & Brandtzæg, 2010 & 79 & $\sqrt{ }$ & & & & $\sqrt{ }$ & & & & & & & & & & & \\
\hline 40 & Wodzicki et al., 2012 & 78 & $\sqrt{ }$ & $\sqrt{ }$ & $\sqrt{ }$ & & & & & & & & & & & $\sqrt{ }$ & & \\
\hline 41 & McGlohon et al., 2008 & 77 & $\sqrt{ }$ & $\sqrt{ }$ & & $\sqrt{ }$ & & & & $\sqrt{ }$ & & & & & & & & \\
\hline 42 & Hines et al., 2006 & 77 & $\sqrt{ }$ & & & & & & & & & & & & & & & \\
\hline 43 & Ackerman et al., 2013 & 76 & $\sqrt{ }$ & & & & & $\sqrt{ }$ & & & & & & & & & & \\
\hline 44 & Boulos et al., 2011 & 76 & & $\sqrt{ }$ & & & $\sqrt{ }$ & & & & & & & & & & & \\
\hline 45 & Sophia van Zyl, 2009 & 76 & $\sqrt{ }$ & & & & & & & & & & & & & & & \\
\hline 46 & Allen et al., 2013 & 73 & & $\sqrt{ }$ & & $\sqrt{ }$ & & & & & & & & & & & & \\
\hline 47 & Kasiviswanathan et al., 2011 & 71 & $\sqrt{ }$ & $\sqrt{ }$ & & & & & & & & & & & & & & \\
\hline 48 & Ma et al., 2011 & 70 & $\sqrt{ }$ & & & & & $\sqrt{ }$ & $\sqrt{ }$ & & & & & & $\sqrt{ }$ & & & \\
\hline 49 & Currie, 2003 & 70 & $\sqrt{ }$ & & & & & & & & & & & & & & & \\
\hline 50 & McGee et al., 2013 & 69 & $\sqrt{ }$ & & & & & & & $\sqrt{ }$ & & $\sqrt{ }$ & & & & & & \\
\hline 51 & Filo et al., 2015 & 68 & & $\sqrt{ }$ & & & & & & & & & & & & & & \\
\hline 52 & Fulk \& Yuan, 2013 & 67 & $\sqrt{ }$ & $\sqrt{ }$ & $\sqrt{ }$ & & & $\sqrt{ }$ & & & & & & & & & & \\
\hline 53 & Poblete et al., 2011 & 67 & $\sqrt{ }$ & $\sqrt{ }$ & $\sqrt{ }$ & & & & & & & $\sqrt{ }$ & & & & & & \\
\hline
\end{tabular}


Table 1

Articles themes (Continued)

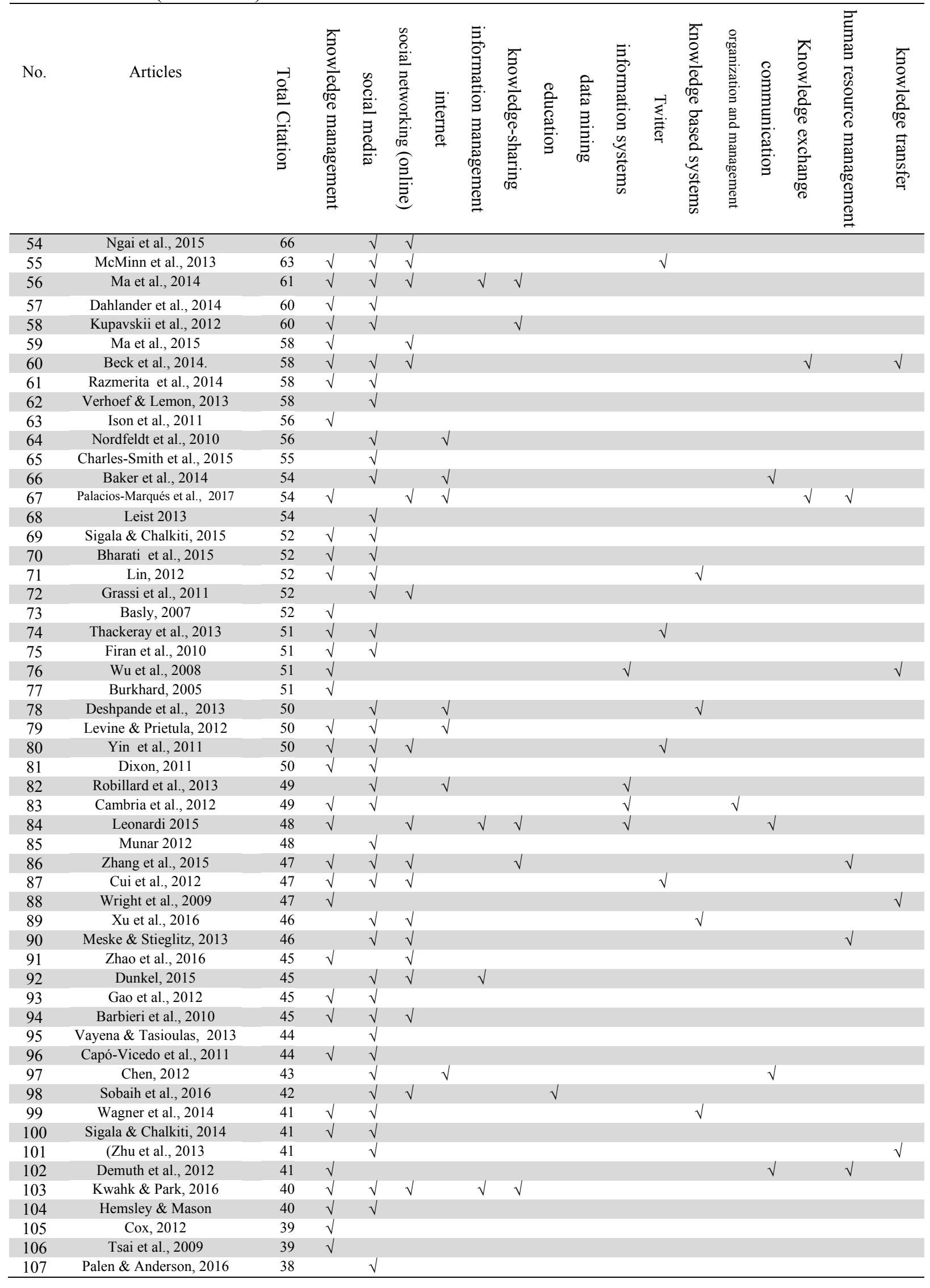


Table 1

Articles themes (Continued)

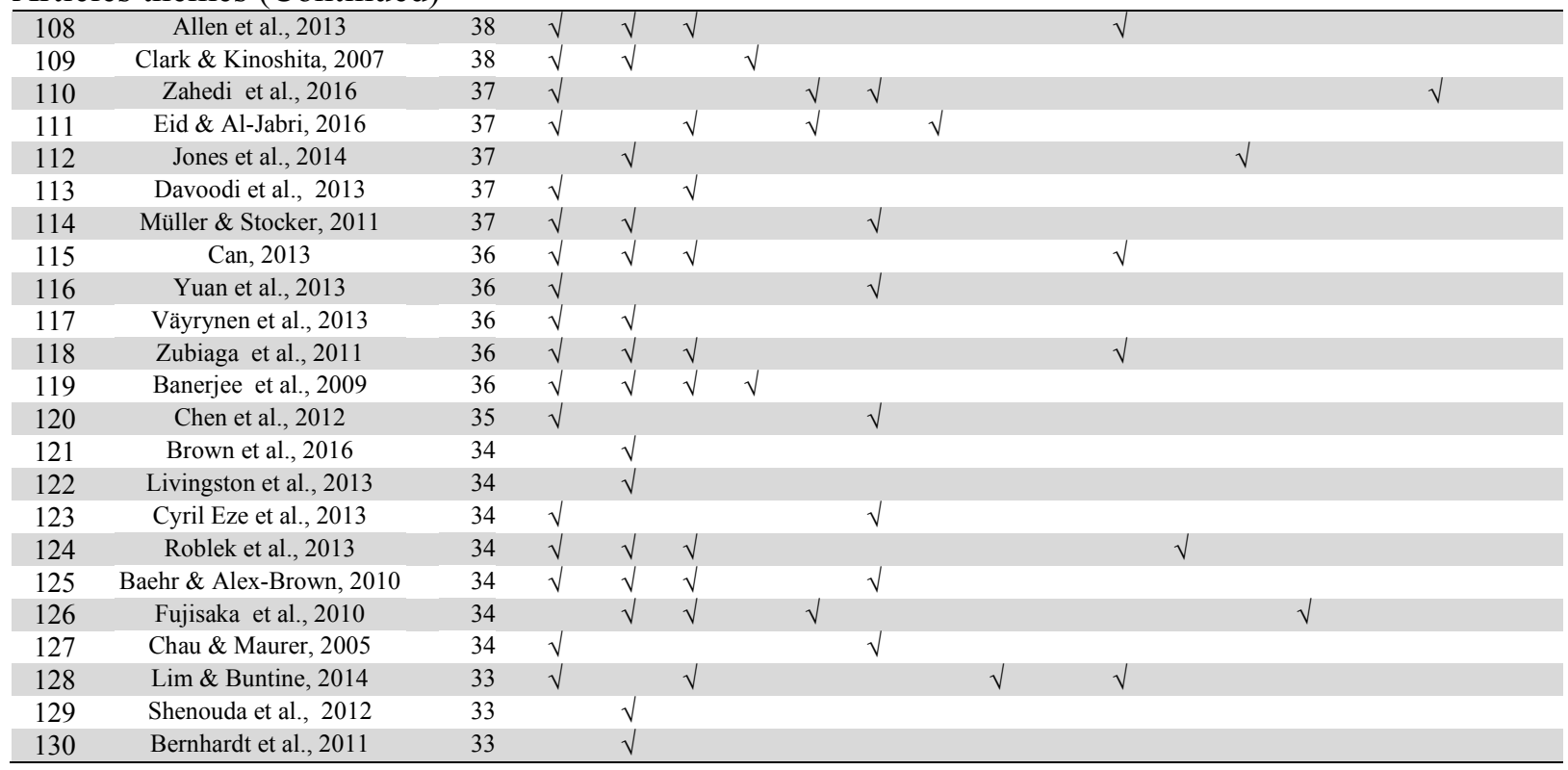

\subsection{The most common keywords and Temporal Analysis}

Table 2 demonstrates some of the most popular keywords used in the studies associated with knowledge management. As observed from the results of Table 1, "knowledge management" and "Social media" and "social networking", are three keywords known in the literature.

Table 2

The most popular keywords used in studies associated with knowledge management and social media

\begin{tabular}{|c|c|c|c|}
\hline words & Occurrences & words & Occurrences \\
\hline knowledge management & 1170 & virtual reality & 54 \\
\hline social media & 1090 & diabetes mellitus & 54 \\
\hline social networking (online) & 673 & interpersonal communication & 53 \\
\hline human & 296 & e-learning & 53 \\
\hline internet & 262 & innovation & 52 \\
\hline humans & 232 & competition & 52 \\
\hline information management & 222 & learning systems & 52 \\
\hline female & 189 & self care & 51 \\
\hline article & 173 & knowledge transfer & 51 \\
\hline male & 155 & qualitative research & 51 \\
\hline knowledge-sharing & 154 & questionnaire & 49 \\
\hline education & 153 & artificial intelligence & 49 \\
\hline information dissemination & 144 & psychology & 48 \\
\hline adult & 135 & online systems & 48 \\
\hline data mining & 125 & social networks & 46 \\
\hline information systems & 109 & motivation & 46 \\
\hline decision making & 104 & social sciences computing & 45 \\
\hline human computer interaction & 95 & aged & 45 \\
\hline knowledge based systems & 95 & health care personnel & 44 \\
\hline procedures & 89 & public health & 44 \\
\hline organization and management & 88 & semantic web & 43 \\
\hline semantics & 88 & health education & 42 \\
\hline communication & 84 & management science & 42 \\
\hline research & 83 & social media platforms & 40 \\
\hline economic and social effects & 80 & design & 40 \\
\hline priority journal & 80 & forecasting & 39 \\
\hline knowledge & 77 & learning & 38 \\
\hline world wide web & 76 & commerce & 38 \\
\hline attitude to health & 75 & natural language processing systems & 38 \\
\hline young adult & 68 & review & 38 \\
\hline behavioral research & 67 & technology & 38 \\
\hline adolescent & 66 & user interfaces & 37 \\
\hline middle aged & 66 & disasters & 37 \\
\hline social network & 65 & medical information & 35 \\
\hline
\end{tabular}


Table 2

The most popular keywords used in studies associated with knowledge management and social media

\begin{tabular}{ccc}
\hline web 2.0 & 65 & management \\
attitudes & 64 & mobile devices \\
health knowledge & 64 & risk management \\
practice & 64 & social interactions \\
health promotion & 63 & social sciences \\
industry & 63 & sustainable development \\
knowledge engineering & 63 & facebook \\
students & 63 & medical education \\
twitter & 63 & risk assessment \\
human resource management & 62 & awareness \\
knowledge acquisition & 61 & big data \\
information retrieval & 59 & collaboration \\
societies and institutions & 59 & sales \\
teaching & 58 & telemedicine \\
websites & 58 & child \\
information technology & 57 & controlled study \\
surveys & 57 & health care \\
social support & 55 & medical informatics \\
united states & 55 & ontology \\
knowledge management & 55 & 33 \\
\hline
\end{tabular}

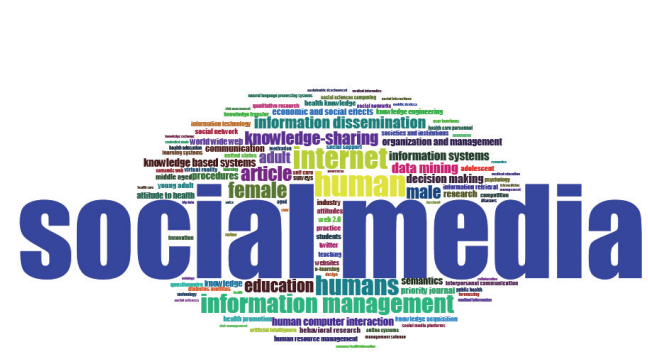

Fig. 2. The frequency of the keywords used in our survey

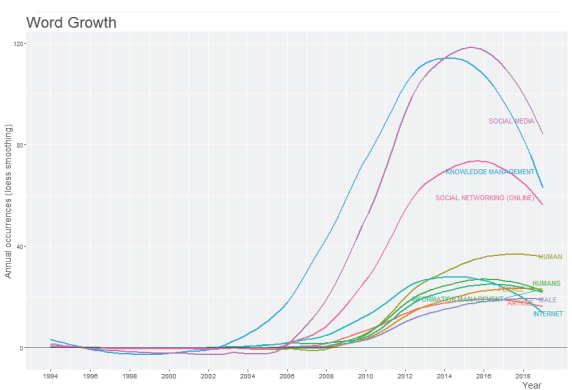

Fig. 3. Word dynamics

As shown in Fig. 2, "knowledge management", "social media", "social networking", "information management", "knowledge-sharing", "human", "information systems", and "internet" are the research hotspots with a high frequency of the keywords used in different project. Zhang et al. (2015) performed a survey based on dynamic topic modeling for monitoring market competition from online text and image data state and reported that social media monitoring could provide companies with temporal summaries of highly overlapped or discriminative topics against their major competitors. There has also been different studies on the analysis of emotions in social media for commercial purposes (e.g. Cakra \& Trisedya, 2016), deep sentiment analysis for analyzing business ads in social media (Jang et al., 2013) and sentiment analysis of Hollywood movies on Twitter (Hodeghatta, 2013). Fig. 3 also presents the world dynamics of different words.

\subsection{Conceptual structure, Co-occurrence network}

A keywords co-occurrence network $(\mathrm{KCN})$ concentrates on understanding the knowledge components and knowledge structure of a scientific/technical field by examining the links between keywords in the literature. Fig. 4 presents the analysis methods based on KCNs used in theoretical and empirical studies to explore research topics and their relationships in selecting scientific fields. If keywords are grouped into the same cluster, they are more likely to reflect identical topics. Each cluster has different number of subject keyword. 


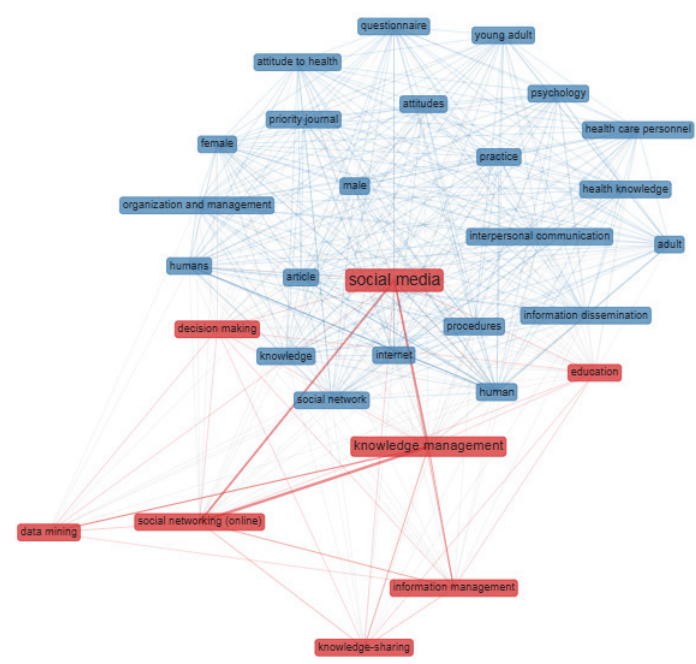

Fig. 4. Co-occurrence network (2011-2019)

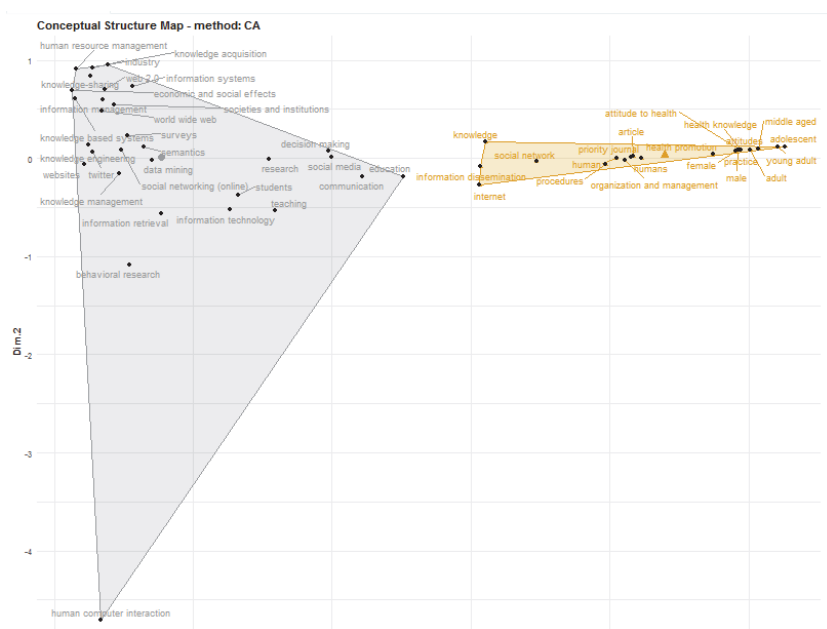

Fig. 5. Conceptual structure Map, method: CA

\subsection{Conceptual structure map, Correspondence analysis}

Co-word analysis aims at representing the conceptual structure of a framework using co-occurrence of words. The words can be replaced by authors' keywords, keywords plus, and terms extracted from titles or abstracts. The conceptual structure function produces three kinds of mapping as listed: conceptual structure map, factorial map of the documents with the highest contributes and factorial map of the most cited documents. Conceptual structure map is shown in Fig.5 and according to our results, cluster 1 has the most keywords, which means the attention of the researchers to the subject matter of the study.

\subsection{Thematic map and historical direct citation network}

Co-word analysis draws clusters of keywords, which are the themes in the study. In the strategic diagram presented in Fig. 7 the vertical axis measures the density - i.e., the strength of the internal links within a cluster represented by a theme -, and the horizontal vertical axis the centrality - i.e. the strength of the links between the theme and other themes in the map. Thematic map is a very intuitive plot and we can analyze themes according to the quadrant in which they are placed:

(Q1) upper-right quadrant: motor-themes;

(Q2) lower-right quadrant: basic themes;

(Q3) lower-left quadrant: emerging or disappearing themes;

(Q4) upper-left quadrant: very specialized/ niche themes.

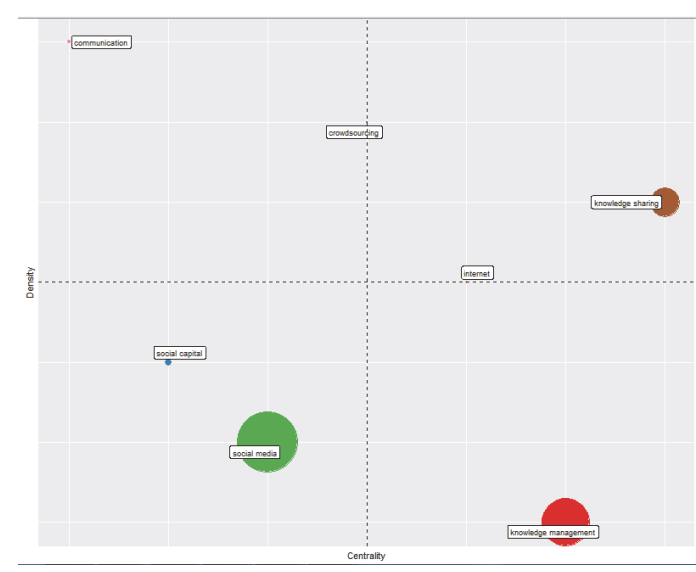

Fig. 6.Thematic map

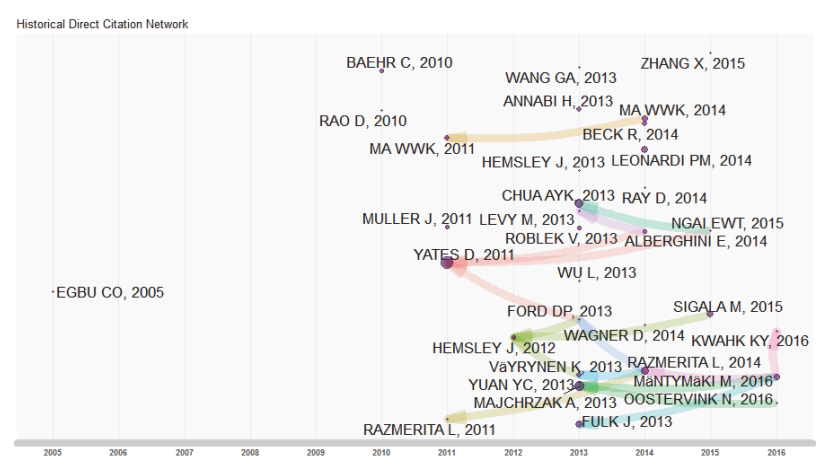

Fig. 7. Historical direct citation network 
According to our survey, knowledge sharing is the most popular topic in our survey. The historiographic map is a graph proposed by E. Garfield to represent a chronological network map of the most relevant direct citations resulting from a bibliographic collection (See Fig. 7). The citation network technique provides the researchers with a new modus operandi which may significantly influence future historiography.

\subsection{Social structure, Contributions of countries}

This figure shows which countries have the highest citation, and which countries have been cited. As we can observe from the results of Fig. 8, there were strong collaboration between the researchers from the United States and other researchers all over the world. Studies show that researchers from the United States (923 articles), UK (306 articles), Germany (224 articles), and the Canada (196) have played a major role in scientific production of knowledge management and social media.

Country Collaboration Map

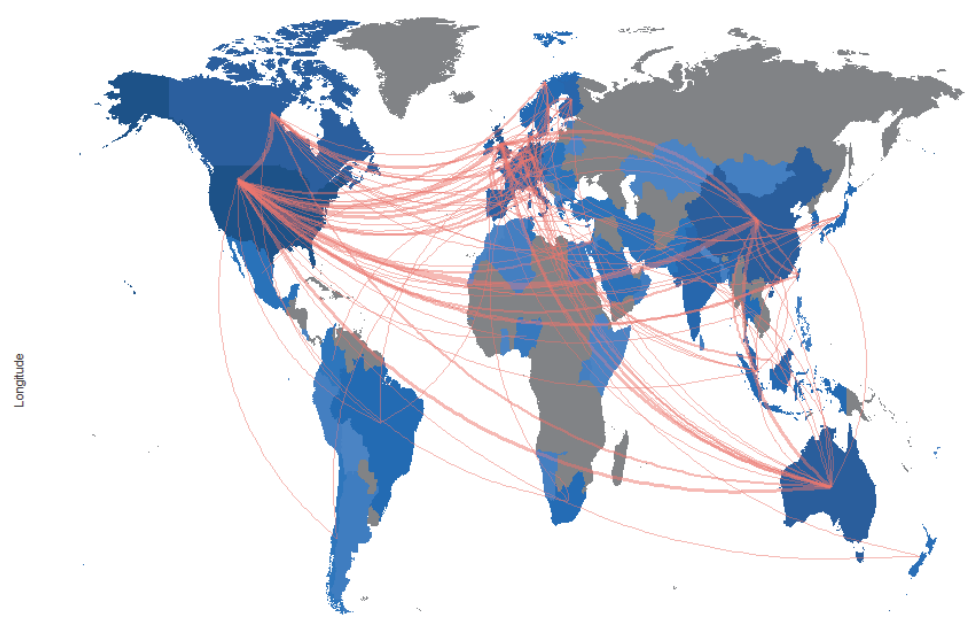

Fig. 8. Country collaboration map

One of the other important areas of research is the study of the scientific production of countries.

\section{Conclusion}

Nowadays, more and more organizations and companies are integrating social software packages into their internal and external communication strategies and redesigning their traditional knowledge management processes to meet the needs and expectations of global conversational markets and net generation knowledge workers. One good way of knowledge management can be accomplished through social media. The present study has concluded that knowledge management could help managers promote the knowledge sharing among employees. This could increase the productivity of the organizations. The results of the present study has indicated that there was an increasing trend on measuring the effects of social media on knowledge management and knowledge sharing.

\section{References}

Aboujaoude, E., Savage, M. W., Starcevic, V., \& Salame, W. O. (2015). Cyberbullying: Review of an old problem gone viral. Journal of adolescent health, 57(1), 10-18.

Ackerman, M. S., Dachtera, J., Pipek, V., \& Wulf, V. (2013). Sharing knowledge and expertise: The CSCW view of knowledge management. Computer Supported Cooperative Work (CSCW),22 (4-6), 531-573. 
Allen, C., Vassilev, I., Kennedy, A., \& Rogers, A. (2016). Long-term condition self-management support in online communities: a meta-synthesis of qualitative papers. Journal of medical Internet research, $18(3)$.

Allen, H. G., Stanton, T. R., Di Pietro, F., \& Moseley, G. L. (2013). Social media release increases dissemination of original articles in the clinical pain sciences. PloS one, 8(7), e68914.

Archambault, D., Greene, D., Cunningham, P., \& Hurley, N. (2011, October). ThemeCrowds: Multiresolution summaries of twitter usage. In Proceedings of the 3rd international workshop on Search and mining user-generated contents (pp. 77-84). ACM.

Aria, M., \& Cuccurullo, C. (2017). bibliometrix: An R-tool for comprehensive science mapping analysis. Journal of Informetrics, 11(4), 959-975.

Asrar-ul-Haq, M., \& Anwar, S. (2016). A systematic review of knowledge management and knowledge sharing: Trends, issues, and challenges. Cogent Business \& Management, 3(1), .1127744

Aurisicchio, M., Bracewell, R., \& Wallace, K. (2010). Understanding how the information requests of aerospace engineering designers influence information-seeking behaviour. Journal of Engineering Design, 21(6), 707-730.

Baehr, C., \& Alex-Brown, K. (2010). Assessing the value of corporate blogs: A social capital perspective. IEEE Transactions on Professional Communication, 53(4), 358-369.

Baker, T. B., Gustafson, D. H., \& Shah, D. (2014). How can research keep up with eHealth? Ten strategies for increasing the timeliness and usefulness of eHealth research. Journal of medical Internet research, 16(2).

Banerjee, N., Chakraborty, D., Dasgupta, K., Mittal, S., Joshi, A., Nagar, S., ... \& Madan, S. (2009, November). User interests in social media sites: an exploration with micro-blogs. In Proceedings of the 18th ACM conference on Information and knowledge management (pp. .1823-1826). ACM.

Barbieri, D., Braga, D., Ceri, S., Della Valle, E., Huang, Y., Tresp, V., ... \& Wermser, H. (2010). Deductive and inductive stream reasoning for semantic social media analytics. IEEE Intelligent Systems, 25(6), 32-41.

Barua, A., Thomas, S. W., \& Hassan, A. E. (2014). What are developers talking about? an analysis of topics and trends in stack overflow. Empirical Software Engineering, 19(3), 619-654.

Basly, S. (2007). The internationalization of family SME: An organizational learning and knowledge development perspective. Baltic Journal of Management, 2(2), 154-180.

Beck, R., Pahlke, I., \& Seebach, C. (2014). Knowledge exchange and symbolic action in social mediaenabled electronic networks of practice: A multilevel perspective on knowledge seekers and contributors. MIS quarterly, 38(4), 1245-1269.

Behringer, N., \& Sassenberg, K. (2015). Introducing social media for knowledge management: Determinants of employees' intentions to adopt new tools. Computers in Human Behavior, 48, 290-296.

Benson, V., Morgan, S., \& Filippaios, F. (2014). Social career management: Social media and employability skills gap. Computers in Human Behavior, 30, 519-525.

Bernhardt, J. M., Alber, J., \& Gold, R. S. (2014). A social media primer for professionals: digital dos and don'ts. Health promotion practice, 15(2), 168-172.

Bernhardt, J. M., Mays, D., \& Kreuter, M. W. (2011). Dissemination 2.0: closing the gap between knowledge and practice with new media and marketing. Journal of health communication, $16(\sup 1)$, 32-44.

Bharati, P., Zhang, W., \& Chaudhury, A. (2015). Better knowledge with social media? Exploring the roles of social capital and organizational knowledge management. Journal of Knowledge Management, 19(3), 456-475.

Bian, J., Yang, Y., \& Chua, T. S. (2013, October). Multimedia summarization for trending topics in microblogs. In Proceedings of the 22nd ACM international conference on Conference on information \& knowledge management (pp. 1807-1812). ACM.

Bidwell, N. J., Winschiers-Theophilus, H., Kapuire, G. K., \& Rehm, M. (2011). Pushing personhood into place: Situating media in rural knowledge in Africa. International Journal of Human-Computer Studies, 69(10), 618-631. 
Bjerregaard, T. (2010). Industry and academia in convergence: Micro-institutional dimensions of $R \& D$ collaboration. Technovation, 30(2), 100-108.

Bombaci, S. P., Farr, C. M., Gallo, H. T., Mangan, A. M., Stinson, L. T., Kaushik, M., \& Pejchar, L. (2016). Using Twitter to communicate conservation science from a professional conference. Conservation Biology, 30(1), 216-225.

Boulos, M. N. K., Resch, B., Crowley, D. N., Breslin, J. G., Sohn, G., Burtner, R., ... \& Chuang, K. Y. S. (2011). Crowdsourcing, citizen sensing and sensor web technologies for public and environmental health surveillance and crisis management: trends, OGC standards and application examples. International journal of health geographics, 10(1), 67.

Brandtzæg, P. B. (2010). Towards a unified Media-User Typology (MUT): A meta-analysis and review of the research literature on media-user typologies. Computers in Human Behavior ,26(5), 940-956.

Brown, J. C., Tuuri, R. E., Akhter, S., Guerra, L. D., Goodman, I. S., Myers, S. R., ... \& Conners, G. P. (2016). Lacerations and embedded needles caused by epinephrine autoinjector use in children. Annals of emergency medicine, 67(3), 307-315.

Brynskov, M., Dalsgaard, P., Ebsen, T., Fritsch, J., Halskov, K., \& Nielsen, R. (2009, August). Staging urban interactions with media façades. In IFIP Conference on Human-Computer Interaction (pp. 154167). Springer, Berlin, Heidelberg.

Burkhard, R. A. (2005). Towards a framework and a model for knowledge visualization: Synergies between information and knowledge visualization. In Knowledge and information visualization (pp. 238-255). Springer, Berlin, Heidelberg.

Cambria, E., Grassi, M., Hussain, A., \& Havasi, C. (2012). Sentic computing for social media marketing. Multimedia tools and applications, 59(2), 557-577.

Can, E. F., Oktay, H., \& Manmatha, R. (2013, October). Predicting retweet count using visual cues. In Proceedings of the 22nd ACM international conference on Conference on information \& knowledge management (pp. 1481-1484). ACM.

Cao, X., Vogel, D. R., Guo, X., Liu, H., \& Gu, J. (2012, January). Understanding the influence of social media in the workplace: An integration of media synchronicity and social capital theories. In 2012 45th Hawaii International Conference on System Sciences (pp. 3938-3947). IEEE.

Capó-Vicedo, J., Mula, J., \& Capó, J. (2011). A social network-based organizational model for improving knowledge management in supply chains. Supply Chain Management: An International Journal, 16(5), 379-388.

Cakra, Y. E., \& Distiawan Trisedya, B. (2016). Stock price prediction using linear regression based on sentiment analysis. In ICACSIS 2015 - 2015 International Conference on Advanced Computer Science and Information Systems, Proceedings (pp. 147-154).

https://doi.org/10.1109/ICACSIS.2015.7415179

Cazier, J. A., Shao, B. B., \& Louis, R. D. S. (2007). Sharing information and building trust through value congruence. Information Systems Frontiers, 9(5), 515-529.

Cha, M., Haddadi, H., Benevenuto, F., \& Gummadi, P. K. (2010). Measuring user influence in twitter: The million follower fallacy. Icwsm, 10(10-17), 30.

Charband, Y., \& Navimipour, N. J. (2016). Online knowledge sharing mechanisms: a systematic review of the state of the art literature and recommendations for future research. Information Systems Frontiers, 18(6), 1131-1151.

Charles-Smith, L. E., Reynolds, T. L., Cameron, M. A., Conway, M., Lau, E. H., Olsen, J. M., ... \& Corley, C. D. (2015). Using social media for actionable disease surveillance and outbreak management: a systematic literature review. PloS one, 10(10), e0139701.

Chau, T., \& Maurer, F. (2005, October). A case study of wiki-based experience repository at a mediumsized software company. In Proceedings of the 3rd international conference on Knowledge capture (pp. 185-186). ACM.

Chen, A. T. (2012). Exploring online support spaces: using cluster analysis to examine breast cancer, diabetes and fibromyalgia support groups. Patient education and counseling, 87(2), 250-257. 
Chen, C. W., Chang, M. L., \& Tseng, C. P. (2012). Retracted: Human factors of knowledge-sharing intention among taiwanese enterprises: A model of hypotheses. Human Factors and Ergonomics in Manufacturing \& Service Industries, 22(4), 362-371.

Chen, F., Tan, P. N., \& Jain, A. K. (2009, November). A co-classification framework for detecting web spam and spammers in social media web sites. In Proceedings of the 18th ACM conference on Information and knowledge management (pp. 1807-1810). ACM.

Chua, A. Y., \& Banerjee, S. (2013). Customer knowledge management via social media: the case of Starbucks. Journal of Knowledge Management, 17(2), 237-249.

Clark, T., \& Kinoshita, J. (2007). Alzforum and SWAN: the present and future of scientific web communities. Briefings in bioinformatics, 8(3), 163-171.

Coccia, M. (2008). Spatial mobility of knowledge transfer and absorptive capacity: analysis and measurement of the impact within the geoeconomic space. The Journal of Technology Transfer, 33(1), 105-122.

Conradi, R., \& Dybå, T. (2001). An empirical study on the utility of formal routines to transfer knowledge and experience. ACM SIGSOFT Software Engineering Notes, 26(5), 268-276.

Cox, A. M. (2012). An exploration of the practice approach and its place in information science. Journal of Information Science, 38(2), 176-188.

Cui, A., Zhang, M., Liu, Y., Ma, S., \& Zhang, K. (2012, October). Discover breaking events with popular hashtags in twitter. In Proceedings of the 21st ACM international conference on Information and knowledge management (pp. 1794-1798). ACM.

Currie, W. L. (2003). A knowledge-based risk assessment framework for evaluating web-enabled application outsourcing projects. International Journal of Project Management, 21(3), 207-217.

Cyril Eze, U., Guan Gan Goh, G., Yih Goh, C., \& Ling Tan, T. (2013). Perspectives of SMEs on knowledge sharing. Vine, 43(2), 210-236.

Dahlander, L., \& Piezunka, H. (2014). Open to suggestions: How organizations elicit suggestions through proactive and reactive attention. Research Policy, 43(5), 812-827.

Darwish, K., Magdy, W., \& Mourad, A. (2012, October). Language processing for arabic microblog retrieval. In Proceedings of the 21st ACM international conference on Information and knowledge management (pp. 2427-2430). ACM.

Davoodi, E., Kianmehr, K., \& Afsharchi, M. (2013). A semantic social network-based expert recommender system. Applied intelligence, 39(1), 1-13.

De Albuquerque, J. P., Herfort, B., Brenning, A., \& Zipf, A. (2015). A geographic approach for combining social media and authoritative data towards identifying useful information for disaster management. International Journal of Geographical Information Science, 29(4), 667-689.

Del Giudice, M., Caputo, F., \& Evangelista, F. (2016). How are decision systems changing? The contribution of social media to the management of decisional liquefaction. Journal of Decision systems, 25(3), 214-226.

Demuth, J. L., Morss, R. E., Morrow, B. H., \& Lazo, J. K. (2012). Creation and communication of hurricane risk information. Bulletin of the American Meteorological Society, 93(8), 1133-1145.

Deshpande, O., Lamba, D. S., Tourn, M., Das, S., Subramaniam, S., Rajaraman, A., ... \& Doan, A. (2013, June). Building, maintaining, and using knowledge bases: a report from the trenches. In Proceedings of the 2013 ACM SIGMOD International Conference on Management of Data (pp. 12091220). ACM.

Dixon, B. E. (2010). Towards e-government 2.0: An assessment of where e-government 2.0 is and where it is headed.

Davenport, T. H., \& Prusak, L. (1998). Working knowledge: How organizations manage what they know. Harvard Business Press.

Dunkel, A. (2015). Visualizing the perceived environment using crowdsourced photo geodata. Landscape and urban planning, 142, 173-186.

Egbu, C. O., Hari, S., \& Renukappa, S. H. (2005). Knowledge management for sustainable competitiveness in small and medium surveying practices. Structural survey, 23(1), 7-21. 
Eid, M. I., \& Al-Jabri, I. M. (2016). Social networking, knowledge sharing, and student learning: The case of university students. Computers \& Education, 99, 14-27.

El Ouirdi, A., El Ouirdi, M., Segers, J., \& Henderickx, E. (2015). Employees' use of social media technologies: a methodological and thematic review. Behaviour \& Information Technology, 34(5), 454464.

Figueiredo, F., Belém, F., Pinto, H., Almeida, J., Gonçalves, M., Fernandes, D., ... \& Cristo, M. (2009, November). Evidence of quality of textual features on the web 2.0. In Proceedings of the 18th ACM conference on Information and knowledge management (pp. 909-918). ACM.

Filo, K., Lock, D., \& Karg, A. (2015). Sport and social media research: A review. Sport management review, 18(2), 166-181.

Firan, C. S., Georgescu, M., Nejdl, W., \& Paiu, R. (2010, October). Bringing order to your photos: eventdriven classification of flickr images based on social knowledge. In Proceedings of the 19th ACM international conference on Information and knowledge management (pp. 189-198). ACM.

Fujisaka, T., Lee, R., \& Sumiya, K. (2010, January). Discovery of user behavior patterns from geo-tagged micro-blogs. In Proceedings of the 4th International Conference on Uniquitous Information Management and Communication (p. 36). ACM.

Fulk, J., \& Yuan, Y. C. (2013). Location, motivation, and social capitalization via enterprise social networking. Journal of Computer-Mediated Communication, 19(1), 20-37.

Gallagher, M., Worth, A., Cunningham-Burley, S., \& Sheikh, A. (2012). Strategies for living with the risk of anaphylaxis in adolescence: qualitative study of young people and their parents. Primary Care Respiratory Journal, 21(4), 392.

Gao, W., Li, P., \& Darwish, K. (2012, October). Joint topic modeling for event summarization across news and social media streams. In Proceedings of the 21st ACM international conference on Information and knowledge management (pp. 1173-1182). ACM.

Gibbs, J. L., Rozaidi, N. A., \& Eisenberg, J. (2013). Overcoming the "ideology of openness": Probing the affordances of social media for organizational knowledge sharing. Journal of Computer-Mediated Communication, 19(1), 102-120.

Gober, P., \& Wheater, H. S. (2015). Debates-Perspectives on socio-hydrology: Modeling flood risk as a public policy problem. Water Resources Research, 51(6), 4782-4788.

Godbole, S., Bhattacharya, I., Gupta, A., \& Verma, A. (2010, October). Building re-usable dictionary repositories for real-world text mining. In Proceedings of the 19th ACM international conference on Information and knowledge management (pp. 1189-1198). ACM.

Goodchild, M. F., \& Janelle, D. G. (2010). Toward critical spatial thinking in the social sciences and humanities. GeoJournal, 75(1), 3-13.

Grassi, M., Cambria, E., Hussain, A., \& Piazza, F. (2011). Sentic web: A new paradigm for managing social media affective information. Cognitive Computation, 3(3), 480-489.

Greif, R., Lockey, A. S., Conaghan, P., Lippert, A., De Vries, W., Monsieurs, K. G., ... \& Castrén, M. (2015). European Resuscitation Council Guidelines for Resuscitation 2015: section 10. Education and implementation of resuscitation. Resuscitation, 95, 288-301.

Grindrod, K., Forgione, A., Tsuyuki, R. T., Gavura, S., \& Giustini, D. (2014). Pharmacy 2.0: a scoping review of social media use in pharmacy. Research in Social and Administrative Pharmacy, 10(1), 256-270.

Hemsley, J., \& Mason, R. M. (2013). Knowledge and knowledge management in the social media age. Journal of Organizational Computing and Electronic Commerce, 23(1-2), 138-167.

Hines, P., Francis, M., \& Found, P. (2006). Towards lean product lifecycle management: a framework for new product development. Journal of Manufacturing Technology Management ,17(7), 866-887.

Hodeghatta, U. R. (2013). Sentiment analysis of Hollywood movies on Twitter. In Proceedings of the 2013 IEEE/ACM International Conference on Advances in Social Networks Analysis and Mining, ASONAM 2013 (pp. 1401-1404). https://doi.org/10.1145/2492517.2500290

Hoffmann, L., Krämer, N. C., Lam-Chi, A., \& Kopp, S. (2009, September). Media equation revisited: do users show polite reactions towards an embodied agent?. In International Workshop on Intelligent Virtual Agents (pp. 159-165). Springer, Berlin, Heidelberg. 
Horvitz, E., \& Mulligan, D. (2015). Data, privacy, and the greater good. Science, 349(6245) ,253-255

Hu, X., Tang, J., \& Liu, H. (2014, July). Leveraging knowledge across media for spammer detection in microblogging. In Proceedings of the 37th international ACM SIGIR conference on Research \& development in information retrieval (pp. 547-556). ACM.

Ioannidis, J. P. (2015). Stealth research: is biomedical innovation happening outside the peer-reviewed literature?. Jama, 313(7), 663-664.

Ison, R., Collins, K., Colvin, J., Jiggins, J., Roggero, P. P., Seddaiu, G., ... \& Zanolla, C. (2011). Sustainable catchment managing in a climate changing world: new integrative modalities for connecting policy makers, scientists and other stakeholders. Water resources management, ,25(15), 3977-3992

Jackson, B. D., Gray, K., Knowles, S. R., \& De Cruz, P. (2016). EHealth technologies in inflammatory bowel disease: a systematic review. Journal of Crohn's and Colitis, 10(9), 1103-,1121

Jagtap, P., Joshi, A., Finin, T., \& Zavala, L. (2011, September). Preserving privacy in context-aware systems. In Semantic computing (ICSC), 2011 fifth IEEE international conference on (pp. 149-153). IEEE.

Jang, H.-J., Sim, J., Lee, Y., \& Kwon, O. (2013). Deep sentiment analysis: Mining the causality between personality-value- attitude for analyzing business ads in social media. Expert Systems with Applications, 40(18), 7492-7503. https://doi.org/10.1016/j.eswa.2013.06.069

Jones, K., Eathington, P., Baldwin, K., \& Sipsma, H. (2014). The impact of health education transmitted via social media or text messaging on adolescent and young adult risky sexual behavior: a systematic review of the literature. Sexually transmitted diseases, 41(7), 413-419.

Juhlin, O., Engström, A., \& Reponen, E. (2010, September). Mobile broadcasting: the whats and hows of live video as a social medium. In Proceedings of the 12th international conference on Human computer interaction with mobile devices and services (pp. 35-44). ACM.

Kane, G., Alavi, M., Labianca, G., \& Borgatti, S. (2012). What's different about social media networks? A framework and research agenda.

Kane, K., Robinson-Combre, J., \& Berge, Z. L. (2010). Tapping into social networking: Collaborating enhances both knowledge management and e-learning. Vine, 40(1), 62-70.

Kapur, G. B., Bezek, S., \& Dyal, J. (2016). Web 2.0 and Internet Social Networking: A New Tool for Disaster Management? Lessons from Taiwan. In Effective Communication During Disasters (pp. 191200). Apple Academic Press.

Kasiviswanathan, S. P., Melville, P., Banerjee, A., \& Sindhwani, V. (2011, October). Emerging topic detection using dictionary learning. In Proceedings of the 20th ACM international conference on Information and knowledge management (pp. 745-754). ACM.

Khoury, M. J., \& Ioannidis, J. P. (2014). Big data meets public health. Science, 346(6213), 1054-1055

Kim, J., \& Hastak, M. (2018). Social network analysis: Characteristics of online social networks after a disaster. International Journal of Information Management, 38(1), 86-96.

Kinsella, S., Murdock, V., \& O'Hare, N. (2011, October). I'm eating a sandwich in Glasgow: modeling locations with tweets. In Proceedings of the 3rd international workshop on Search and mining usergenerated contents (pp. 61-68). ACM.

Konstantinidis, S., Fernandez-Luque, L., Bamidis, P., \& Karlsen, R. (2013). The role of taxonomies in social media and the semantic web for health education. Methods of information in medicine, 52(02), 168-179.

Kupavskii, A., Ostroumova, L., Umnov, A., Usachev, S., Serdyukov, P., Gusev, G., \& Kustarev, A. (2012, October). Prediction of retweet cascade size over time. In Proceedings of the 21st ACM international conference on Information and knowledge management (pp. 2335-,2338). ACM

Kwahk, K. Y., \& Park, D. H. (2016). The effects of network sharing on knowledge-sharing activities and job performance in enterprise social media environments. Computers in Human Behavior, 55, 826839.

Laboreiro, G., Sarmento, L., Teixeira, J., \& Oliveira, E. (2010, October). Tokenizing micro-blogging messages using a text classification approach. In Proceedings of the fourth workshop on Analytics for noisy unstructured text data (pp. 81-88). ACM. 
Lakkaraju, H., \& Ajmera, J. (2011, October). Attention prediction on social media brand pages. In Proceedings of the 20th ACM international conference on Information and knowledge management (pp. 2157-2160). ACM.

Lau, A. S. (2011). Hospital-based nurses' perceptions of the adoption of Web 2.0 tools for knowledge sharing, learning, social interaction and the production of collective intelligence. Journal of medical Internet research, 13(4).

Lee, Y., Kozar, K. A., \& Larsen, K. R. (2009). Avatar e-mail versus traditional e-mail: Perceptual difference and media selection difference. Decision Support Systems, 46(2), 451-,467

Leist, A. K. (2013). Social media use of older adults: a mini-review. Gerontology, 59(4), 378-,384

Leonardi, P. M. (2014). Social media, knowledge sharing, and innovation: Toward a theory of communication visibility. Information systems research, 25(4), 796-816.

Leonardi, P. M. (2015). Ambient awareness and knowledge acquisition: using social media to learn 'who knows what' and 'who knows whom'.

Levine, S. S., \& Prietula, M. J. (2012). How knowledge transfer impacts performance: A multilevel model of benefits and liabilities. Organization Science, 23(6), 1748-1766.

Li, J., Hu, X., Tang, J., \& Liu, H. (2015, October). Unsupervised streaming feature selection in social media. In Proceedings of the 24th ACM International on Conference on Information and Knowledge Management (pp. 1041-1050). ACM.

Lim, K. W., \& Buntine, W. (2014, November). Twitter opinion topic model: Extracting product opinions from tweets by leveraging hashtags and sentiment lexicon. In Proceedings of the 23rd ACM international conference on conference on information and knowledge management (pp.1319-1328). ACM

Lin, C., Lin, C., Li, J., Wang, D., Chen, Y., \& Li, T. (2012, October). Generating event storylines from microblogs. In Proceedings of the 21st ACM international conference on Information and knowledge management (pp. 175-184). ACM.

Lindtner, S., Chen, J., Hayes, G. R., \& Dourish, P. (2011). Towards a framework of publics: Re-encountering media sharing and its user. ACM Transactions on Computer-Human Interaction (TOCHI), $18(2), 5$.

Livingston, J. D., Tugwell, A., Korf-Uzan, K., Cianfrone, M., \& Coniglio, C. (2013). Evaluation of a campaign to improve awareness and attitudes of young people towards mental health issues. Social psychiatry and psychiatric epidemiology, 48(6), 965-973.

Ma, J., Gao, W., Wei, Z., Lu, Y., \& Wong, K. F. (2015, October). Detect rumors using time series of social context information on microblogging websites. In Proceedings of the 24th ACM International on Conference on Information and Knowledge Management (pp. 1751-,1754). ACM

Ma, W. W., \& Chan, A. (2014). Knowledge sharing and social media: Altruism, perceived online attachment motivation, and perceived online relationship commitment. Computers in Human Behavior, 39, 51-58.

Ma, W. W., \& Yuen, A. H. (2011). Understanding online knowledge sharing: An interpersonal relationship perspective. Computers \& Education, 56(1), 210-219.

Mairs, K., McNeil, H., McLeod, J., Prorok, J. C., \& Stolee, P. (2013). Online strategies to facilitate health-related knowledge transfer: a systematic search and review. Health Information \& Libraries Journal, 30(4), 261-277.

Majchrzak, A., Faraj, S., Kane, G. C., \& Azad, B. (2013). The contradictory influence of social media affordances on online communal knowledge sharing. Journal of Computer-Mediated Communication, 19(1), 38-55.

Mäntymäki, M., \& Riemer, K. (2016). Enterprise social networking: A knowledge management perspective. International Journal of Information Management, 36(6), 1042-,1052

Marlow, J., \& Dabbish, L. (2014, February). From rookie to all-star: professional development in a graphic design social networking site. In Proceedings of the 17th ACM conference on Computer supported cooperative work \& social computing (pp. 922-933). ACM.

Martín-de-Castro, G., Delgado-Verde, M., López-Sáez, P., \& Navas-López, J. E. (2011). Towards 'an intellectual capital-based view of the firm': origins and nature. Journal of business ethics, 98(4), 649662. 
Martinelli, A., Meyer, M., \& Von Tunzelmann, N. (2008). Becoming an entrepreneurial university? A case study of knowledge exchange relationships and faculty attitudes in a medium-sized, researchoriented university. The Journal of Technology Transfer, 33(3), 259-,283

McAdam, R., \& Reid, R. (2001). SME and large organisation perceptions of knowledge management: comparisons and contrasts. Journal of knowledge management, 5(3), 231-241.

McGee, J., Caverlee, J. A., \& Cheng, Z. (2011, October). A geographic study of tie strength in social media. In Proceedings of the 20th ACM international conference on Information and knowledge management (pp. 2333-2336). ACM.

McGee, J., Caverlee, J., \& Cheng, Z. (2013, October). Location prediction in social media based on tie strength. In Proceedings of the 22nd ACM international conference on Information \& Knowledge Management (pp. 459-468). ACM.

McGlohon, M., Akoglu, L., \& Faloutsos, C. (2008, August). Weighted graphs and disconnected components: patterns and a generator. In Proceedings of the 14th ACM SIGKDD international conference on Knowledge discovery and data mining (pp. 524-532). ACM.

McMinn, A. J., Moshfeghi, Y., \& Jose, J. M. (2013, October). Building a large-scale corpus for evaluating event detection on twitter. In Proceedings of the 22nd ACM international conference on Information \& Knowledge Management (pp. 409-418). ACM.

Meske, C., \& Stieglitz, S. (2013, June). Adoption and use of social media in small and medium-sized enterprises. In working conference on practice-driven research on enterprise transformation (pp. 6175). Springer, Berlin, Heidelberg.

Miesing, P., Kriger, M. P., \& Slough, N. (2007). Towards a model of effective knowledge transfer within transnationals: The case of Chinese foreign invested enterprises. The Journal of Technology Transfer, 32(1-2), 109-122.

Müller, J., \& Stocker, A. (2011). Enterprise microblogging for advanced knowledge sharing: The references@BT case study.J.UCS, 17(4),532-547.

Munar, A. M. (2012). Social media strategies and destination management. Scandinavian Journal of Hospitality and Tourism, 12(2), 101-120.

Murphy, G., \& Salomone, S. (2013). Using social media to facilitate knowledge transfer in complex engineering environments: a primer for educators. European Journal of Engineering Education, 38(1), 70-84.

Ngai, E. W., Moon, K. L. K., Lam, S. S., Chin, E. S., \& Tao, S. S. (2015). Social media models, technologies, and applications: an academic review and case study. Industrial Management \& Data Systems, $115(5), 769-802$.

Nguyen, L., Torlina, L., Peszynski, K., \& Corbitt, B. (2006). Power relations in virtual communities: An ethnographic study. Electronic Commerce Research, 6(1), 21-37.

Nordfeldt, S., Hanberger, L., \& Berterö, C. (2010). Patient and parent views on a Web 2.0 Diabetes Portal - the management tool, the generator, and the gatekeeper: qualitative study. Journal of medical Internet research, 12(2).

O’Donnell, D., O'Regan, P., \& Coates, B. (2000). Intellectual capital: a Habermasian introduction. Journal of intellectual capital, 1(2), 187-200.

Oktay, H., Taylor, B. J., \& Jensen, D. D. (2010, July). Causal discovery in social media using quasiexperimental designs. In Proceedings of the First Workshop on Social Media Analytics (pp. 1-9). ACM.

Olsen, K. H. (2007). The clean development mechanism's contribution to sustainable development: a review of the literature. Climatic change, 84(1), 59-73.

Palacios-Marqués, D., Soto-Acosta, P., \& Merigó, J. M. (2015). Analyzing the effects of technological, organizational and competition factors on Web knowledge exchange in SMEs. Telematics and Informatics, 32(1), 23-32.

Palen, L., \& Anderson, K. M. (2016). Crisis informatics-New data for extraordinary times. Science, 353(6296), 224-225.

Parganas, P., Anagnostopoulos, C., \& Chadwick, S. (2015). 'You'll never tweet alone': Managing sports brands through social media. Journal of Brand Management, 22(7), 551-568. 
Peersman, C., Daelemans, W., \& Van Vaerenbergh, L. (2011, October). Predicting age and gender in online social networks. In Proceedings of the 3rd international workshop on Search and mining usergenerated contents (pp. 37-44). ACM.

Pigg, S. (2014). Coordinating constant invention: Social media's role in distributed work. Technical Communication Quarterly, 23(2), 69-87.

Poblete, B., Garcia, R., Mendoza, M., \& Jaimes, A. (2011, October). Do all birds tweet the same?: characterizing twitter around the world. In Proceedings of the 20th ACM international conference on Information and knowledge management (pp. 1025-1030). ACM.

Price, D., Fletcher, M., \& Van Der Molen, T. (2014). Asthma control and management in 8,000 European patients: the REcognise Asthma and LInk to Symptoms and Experience (REALISE) survey. NPJ primary care respiratory medicine, 24, 14009.

Qian, M., \& Zhai, C. (2014, November). Unsupervised feature selection for multi-view clustering on text-image web news data. In Proceedings of the 23rd ACM international conference on conference on information and knowledge management (pp. 1963-1966). ACM.

Rastogi, P. N. (2000). Knowledge management and intellectual capital-the new virtuous reality of competitiveness. Human systems management, 19(1), 39-48.

Razmerita, L., \& Kirchner, K. (2011). How wikis can be used to manage knowledge in SMEs: A case study. Business Information Review, 28(3), 175-178.

Razmerita, L., Kirchner, K., \& Nabeth, T. (2014). Social media in organizations: leveraging personal and collective knowledge processes. Journal of Organizational Computing and Electronic Commerce, 24(1), 74-93.

Reinhold, O., \& Alt, R. (2011, June). Analytical Social CRM: Concept and Tool Support. In Bled eConference (p. 50).

Robillard, J. M., Johnson, T. W., Hennessey, C., Beattie, B. L., \& Illes, J. (2013). Aging 2.0: health information about dementia on Twitter. PLoS One, 8(7), e69861.

Roblek, V., Pejić Bach, M., Meško, M., \& Bertoncelj, A. (2013). The impact of social media to value added in knowledge-based industries. Kybernetes, 42(4), 554-568.

Saerbeck, M., Schut, T., Bartneck, C., \& Janse, M. D. (2010, April). Expressive robots in education: varying the degree of social supportive behavior of a robotic tutor. In Proceedings of the SIGCHI Conference on Human Factors in Computing Systems (pp. 1613-1622). ACM.

Saez-Trumper, D., Castillo, C., \& Lalmas, M. (2013, October). Social media news communities: gatekeeping, coverage, and statement bias. In Proceedings of the 22nd ACM international conference on Conference on information \& knowledge management (pp. 1679-,1684). ACM

Sampson, J. A. (1940). The development of the implantation theory for the origin of peritoneal endometriosis. American Journal of Obstetrics \& Gynecology, 40(4), 549-557.

Saridakis, G., Benson, V., Ezingeard, J. N., \& Tennakoon, H. (2016). Individual information security, user behaviour and cyber victimisation: An empirical study of social networking users. Technological Forecasting and Social Change, 102, 320-330.

Sartorius, N., Gaebel, W., CLEVELAND, H. R., Stuart, H., Akiyama, T., ARBOLEDA-FLÓREZ, J. U. L. I. O., ... \& Suzuki, Y. (2010). WPA guidance on how to combat stigmatization of psychiatry and psychiatrists. World Psychiatry, 9(3), 131-144.

Schäfer, L., Valle, C., \& Prinz, W. (2004, October). Group storytelling for team awareness and entertainment. In Proceedings of the third Nordic conference on Human-computer interaction (pp. 441-444). ACM.

Seebach, C. (2012, January). Searching for Answers--Knowledge Exchange through Social Media in Organizations. In System Science (HICSS), 2012 45th Hawaii International Conference on (pp. 39083917). IEEE.

Shenouda, C., Hendrickson, P., Davenport, K., Barber, J., \& Bell, K. R. (2012). The effects of concussion legislation one year later-what have we learned: a descriptive pilot survey of youth soccer player associates. $P M \& R, 4(6), 427-435$. 
Shivakoti, G. P., \& Schmidt-Vogt, D. (2009). Livelihood change and livelihood sustainability in the uplands of Lembang subwatershed, West Sumatra, Indonesia, in a changing natural resource management context. Environmental management, 43(1), 84.

Shoham, S., \& Perry, M. (2009). Knowledge management as a mechanism for technological and organizational change management in Israeli universities. Higher education, 57(2), 227-,246

Sigala, M., \& Chalkiti, K. (2014). Investigating the exploitation of web 2.0 for knowledge management in the Greek tourism industry: An utilisation-importance analysis. Computers in Human Behavior, 30, 800-812.

Sigala, M., \& Chalkiti, K. (2015). Knowledge management, social media and employee creativity. International Journal of Hospitality Management, 45, 44-58.

Sobaih, A. E. E., Moustafa, M. A., Ghandforoush, P., \& Khan, M. (2016). To use or not to use? Social media in higher education in developing countries. Computers in Human Behavior, 58, ,296-305.

Sizov, S. (2010, February). Geofolk: latent spatial semantics in web 2.0 social media. In Proceedings of the third ACM international conference on Web search and data mining (pp. 281-290). ACM.

Sophia van Zyl, A. (2009). The impact of Social Networking 2.0 on organisations. The Electronic Library, 27(6), 906-918.

Soto-Acosta, P., Popa, S., \& Palacios-Marqués, D. (2017). Social web knowledge sharing and innovation performance in knowledge-intensive manufacturing SMEs. The Journal of Technology Transfer, $42(2), 425-440$.

Sousa, D., Sarmento, L., \& Mendes Rodrigues, E. (2010, October). Characterization of the twitter@, replies network: are user ties social or topical?. In Proceedings of the 2 nd international workshop on Search and mining user-generated contents (pp. 63-70). ACM.

Stellefson, M., Chaney, B., Barry, A. E., Chavarria, E., Tennant, B., Walsh-Childers, K., ... \& Zagora, J. (2013). Web 2.0 chronic disease self-management for older adults: a systematic review. Journal of medical Internet research, 15(2).

Straub, D. W. (1994). The Effect of Culture on IT Diffusion: E-Mail and FAX in Japan and the US. Information Systems Research, 5(1), 23-47.

Tang, L., \& Liu, H. (2009, November). Scalable learning of collective behavior based on sparse social dimensions. In Proceedings of the 18th ACM conference on Information and knowledge management (pp. 1107-1116). ACM.

Tang, L., \& Liu, H. (2009, November). Scalable learning of collective behavior based on sparse social dimensions. In Proceedings of the 18th ACM conference on Information and knowledge management (pp. 1107-1116). ACM.

Thackeray, R., Burton, S. H., Giraud-Carrier, C., Rollins, S., \& Draper, C. R. (2013). Using Twitter for breast cancer prevention: an analysis of breast cancer awareness month. BMC cancer, 13(1), 508.

Tredinnick, L. (2006). Web 2.0 and Business: A pointer to the intranets of the future?. Business information review, 23(4), 228-234.

Tsai, F. S., Hsieh, L. H., Fang, S. C., \& Lin, J. L. (2009). The co-evolution of business incubation and national innovation systems in Taiwan. Technological Forecasting and Social Change, 76(5), 629643.

Tsitsi Chikandiwa, S., Contogiannis, E., \& Jembere, E. (2013). The adoption of social media marketing in South African banks. European Business Review, 25(4), 365-381.

Vayena, E., \& Tasioulas, J. (2013). Adapting standards: ethical oversight of participant-led health research. PLoS medicine, 10(3), e1001402.

Väyrynen, K., Hekkala, R., \& Liias, T. (2013). Knowledge protection challenges of social media encountered by organizations. Journal of Organizational Computing and Electronic Commerce, 23(1-2), 3455.

Verhoef, P. C., \& Lemon, K. N. (2013). Successful customer value management: Key lessons and emerging trends. European Management Journal, 31(1), 1-15.

Vuori, V., \& Okkonen, J. (2012). Refining information and knowledge by social media applications: Adding value by insight. Vine, 42(1), 117-128. 
Wagner, D., Vollmar, G., \& Wagner, H. T. (2014). The impact of information technology on knowledge creation: An affordance approach to social media. Journal of Enterprise Information Management, 27(1), 31-44.

Wanas, N., El-Saban, M., Ashour, H., \& Ammar, W. (2008, October). Automatic scoring of online discussion posts. In Proceedings of the 2nd ACM workshop on Information credibility on the web (pp. 19-26). ACM.

Wang, G. A., Jiao, J., Abrahams, A. S., Fan, W., \& Zhang, Z. (2013). ExpertRank: A topic-aware expert finding algorithm for online knowledge communities. Decision Support Systems, ,54(3), 1442-1451

Wang, M. (2011). Integrating organizational, social, and individual perspectives in Web 2.0-based workplace e-learning. Information Systems Frontiers, 13(2), 191-205.

Wodzicki, K., Schwämmlein, E., \& Moskaliuk, J. (2012). "Actually, I wanted to learn": study-related knowledge exchange on social networking sites. The Internet and Higher Education, ,15(1), 9-14

Wright, M., Piva, E., Mosey, S., \& Lockett, A. (2009). Academic entrepreneurship and business schools. The Journal of Technology Transfer, 34(6), 560-587.

$\mathrm{Wu}, \mathrm{L}$. (2013). Social network effects on productivity and job security: Evidence from the adoption of a social networking tool. Information systems research, 24(1), 30-51.

Wu, L., Waber, B., Aral, S., Brynjolfsson, E., \& Pentland, A. (2008). Mining face-to-face interaction networks using sociometric badges: Predicting productivity in an it configuration task.

Xu, Z., Zhang, H., Hu, C., Mei, L., Xuan, J., Choo, K. K. R., ... \& Zhu, Y. (2016). Building knowledge base of urban emergency events based on crowdsourcing of social media. Concurrency and Computation: Practice and experience, 28(15), 4038-4052.

Yates, D., \& Paquette, S. (2010, October). Emergency knowledge management and social media technologies: A case study of the 2010 Haitian earthquake. In Proceedings of the 73rd ASIS\&T Annual Meeting on Navigating Streams in an Information Ecosystem-Volume 47 (p. ,42). American Society for Information Science

Yin, D., Hong, L., \& Davison, B. D. (2011, October). Structural link analysis and prediction in microblogs. In Proceedings of the 20th ACM international conference on Information and knowledge management (pp. 1163-1168). ACM.

Yuan, Y. C., Zhao, X., Liao, Q., \& Chi, C. (2013). The use of different information and communication technologies to support knowledge sharing in organizations: From e-mail to micro-blogging. Journal of the American Society for Information Science and Technology, ,64(8), 1659-1670

Zahedi, M., Shahin, M., \& Babar, M. A. (2016). A systematic review of knowledge sharing challenges and practices in global software development. International Journal of Information Management, 36(6), 995-1019.

Zarghami, M., Abrishamchi, A., \& Ardakanian, R. (2008). Multi-criteria decision making for integrated urban water management. Water Resources Management, 22(8), 1017-1029.

Zhang, X., Gao, Y., Yan, X., de Pablos, P. O., Sun, Y., \& Cao, X. (2015). From e-learning to sociallearning: Mapping development of studies on social media-supported knowledge management. Computers in Human Behavior, 51, 803-811.

Zhao, W. X., Li, S., He, Y., Chang, E. Y., Wen, J. R., \& Li, X. (2016). Connecting social media to ecommerce: Cold-start product recommendation using microblogging information. IEEE Transactions on Knowledge and Data Engineering, 28(5), 1147-1159.

Zhu, Y., Zhong, E., Pan, S. J., Wang, X., Zhou, M., \& Yang, Q. (2013, October). Predicting user activity level in social networks. In Proceedings of the 22nd ACM international conference on Information \& Knowledge Management (pp. 159-168). ACM.

Zubiaga, A., Spina, D., Fresno, V., \& Martínez, R. (2011, October). Classifying trending topics: a typology of conversation triggers on twitter. In Proceedings of the 20th ACM international conference on Information and knowledge management (pp. 2461-2464). ACM. 
(C) 2019 by the authors; licensee Growing Science, Canada. This is an open access article distributed under the terms and conditions of the Creative Commons Attribution (CC-BY) license (http://creativecommons.org/licenses/by/4.0/). 